University of Louisville

ThinkIR: The University of Louisville's Institutional Repository

\title{
A retrospective study on the effect of immunotherapy treatment on nasal polyposis.
}

Johanna Haejean Yun

University of Louisville

Follow this and additional works at: https://ir.library.louisville.edu/honors

Part of the Biological and Physical Anthropology Commons

\section{Recommended Citation}

Yun, Johanna Haejean, "A retrospective study on the effect of immunotherapy treatment on nasal polyposis." (2014). College of Arts \& Sciences Senior Honors Theses. Paper 74.

http://doi.org/10.18297/honors/74

This Senior Honors Thesis is brought to you for free and open access by the College of Arts \& Sciences at ThinkIR: The University of Louisville's Institutional Repository. It has been accepted for inclusion in College of Arts \& Sciences Senior Honors Theses by an authorized administrator of ThinkIR: The University of Louisville's Institutional Repository. This title appears here courtesy of the author, who has retained all other copyrights. For more information, please contact thinkir@louisville.edu. 


\title{
A Retrospective Study on the Effect of Immunotherapy Treatment on Nasal Polyposis
}

\author{
By
}

Johanna Haejean Yun

Submitted in partial fulfillment of the requirements

for Graduation summa cum laude

and

for Graduation with Honors from the Department of Biology/Anthropology

University of Louisville

May 2014 


\section{Table of Contents}

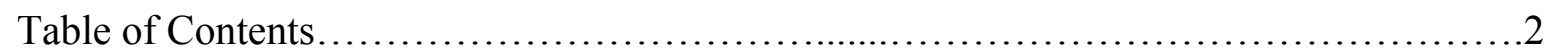

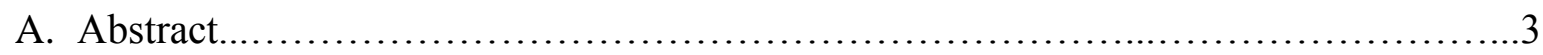

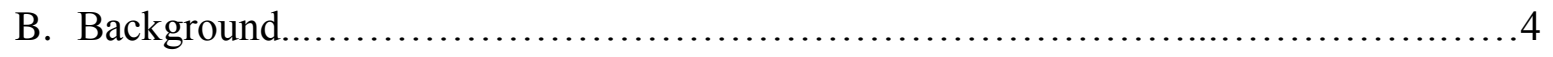

1. History and Pathophysiology of Nasal Polyposis............................4

2. Current Hypotheses on Multifactorial Causes of Nasal Polyps................9

2.1. Infection............................................... 9

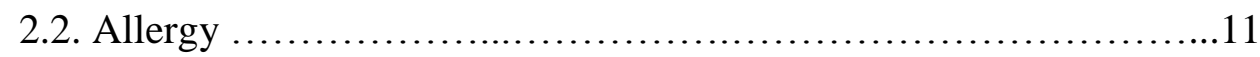

2.3. Asthma................................................... 12

2.4. Aspirin Hypersensitivity....................................... 13

3. Treatment of Nasal Polyposis.......................................... 14

4. Functional Endoscopic Sinus Surgery and CT Scoring...................... 15

5. Treatment of Allergies with Immunotherapy.............................18

C. Research Hypotheses..................................................... 19

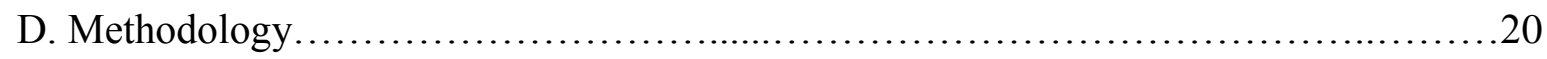

1. Data Collection........................................................20

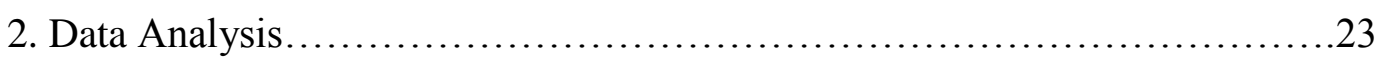

E. Results................................................................24

F. Strengths $\&$ Limitations........................................................ 31

G. Conclusions........................................................... 33

H. Appendix ..................................................................

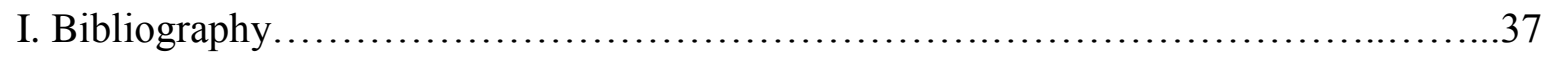




\section{A. ABSTRACT:}

Inside the paranasal sinuses, multiple saclike masses protrude from the lining, blocking one's sense of taste and smell, clogging one's nose with nasal congestion, and causing a continuous runny nose with postnasal drip. This is a common case of nasal polyposis. Nasal polyposis affects up to four percent of the general population, making it one of the most common chronic diseases of the upper respiratory tract (Settipane 1996). Moreover, in cadaveric studies, the prevalence has been as high as $40 \%$ (Larson et al 1994). Nasal polyps commonly occur in adults over the age of 40 , predominantly in males — with a 2:1 ratio of males to females. Young children with nasal polyps typically are diagnosed with cystic fibrosis (Mayo Clinic Staff 2011).

Though polyps can be removed through Functional Endoscopic Sinus Surgery, they redevelop over time. In addition to surgical methods, physicians prescribe oral and nasal corticosteroids and antileukotrienes. Though immunotherapy treatment is not a traditional form of treatment in medical literature, there are many studies indicating that allergies may contribute to nasal polyposis. In Kentucky, where there are high counts of pollen, there may be a positive association between immunotherapy and nasal polyp recurrence. This local, retrospective study of 90 patients, with pathologically reported nasal polyps, researched any correlations between the recurrence of polyps and the use of immunotherapy treatment. It was found that immunotherapy treatment had no statistically significant effect on the number of revision surgeries or on the time to the recurrence of nasal polyps. Asthma and aspirin hypersensitivity had statistically significant correlations with higher CT scores or more severe disease. Though allergies were dominant in most of the sample population, eosinophilic presence in polyp tissue was not found to have any significant effect on the CT score (based on the Lund-Mackay staging system). Increasing the CT score indicated a shorter time to a polyp recurrence. Thus, it is recommended that patients 
seek immediate care of polyps at lower stages of disease. More studies need to be conducted to determine any significant associations with immunotherapy treatment and nasal polyposis recurrence. Also, further studies are needed to verify the effectiveness of the recommendation for patients to treat polyps at the earliest stage to prevent further removals, chronic symptoms, and financial investments.

\section{B. BACKGROUND:}

\section{History and Pathophysiology of Nasal Polyposis}

The first recorded diagnosis of nasal polyposis is found in Egyptian literature dating approximately 2,000 years BCE. In ancient Hindu and Egyptian medical texts, rhinologic procedures date back to $700 \mathrm{BCE}$. Egyptians were familiar with the nasal cavity, due to the routine removal of cranial contents through the nose to prevent facial disfiguration during the mummification process (Baroodi and Emani 2010). Hippocrates, another early documenter of nasal polyps, was known for having referred to "nasal growths" as "polypus" due to their resemblance to the sea-polyp (Baroodi and Emani 2010). This name, "polypus," remains as the name of the growth today.

In the early first century, polyps were thought to be "affected by moist weather and warm seasons," with many believing that these nasal masses were a systemic disease (Baroodi and Emani 2010). Today, with advanced scientific knowledge, the pathophysiology of polyps is becoming much clearer. Now, it is known that nasal polyposis is a chronic inflammatory disease of the mucus-secreting tissue in the nasal sinuses. From the anterior ethmoid sinuses, the disease can descend to the middle turbinate and the lateral nasal wall into the nasal cavity (See Images 1, $2, \& 3)$. The benign, dropsical polyps protrude from the mucosal lining of columnar epithelial 
cells, containing mostly goblet cells, which secrete mucus to protect the body from invading pathogens.

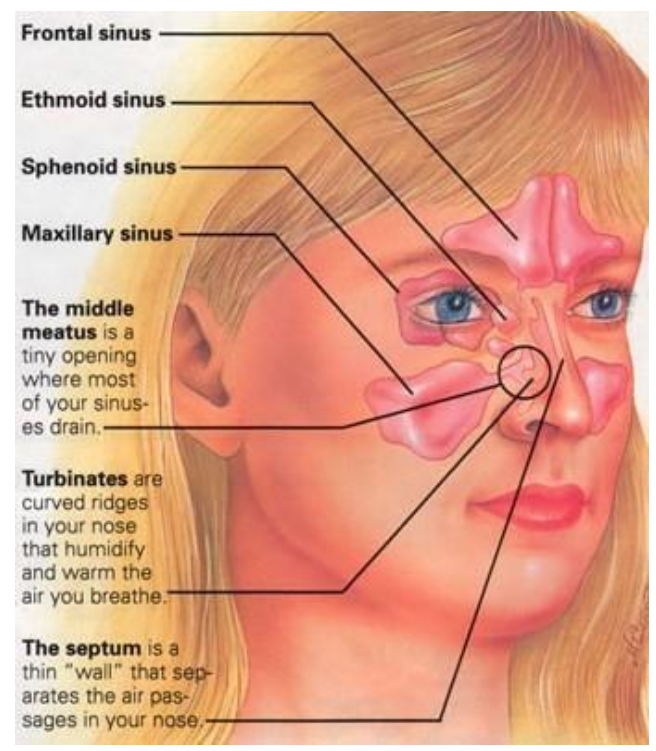

(C/V ENT Surgical Group 2009) 1

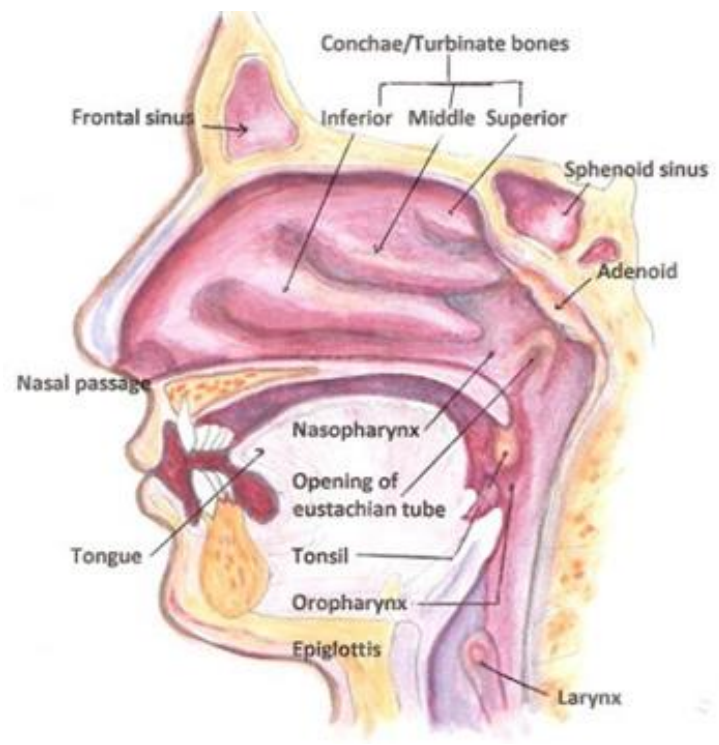

(Learn Human Anatomy 2014)

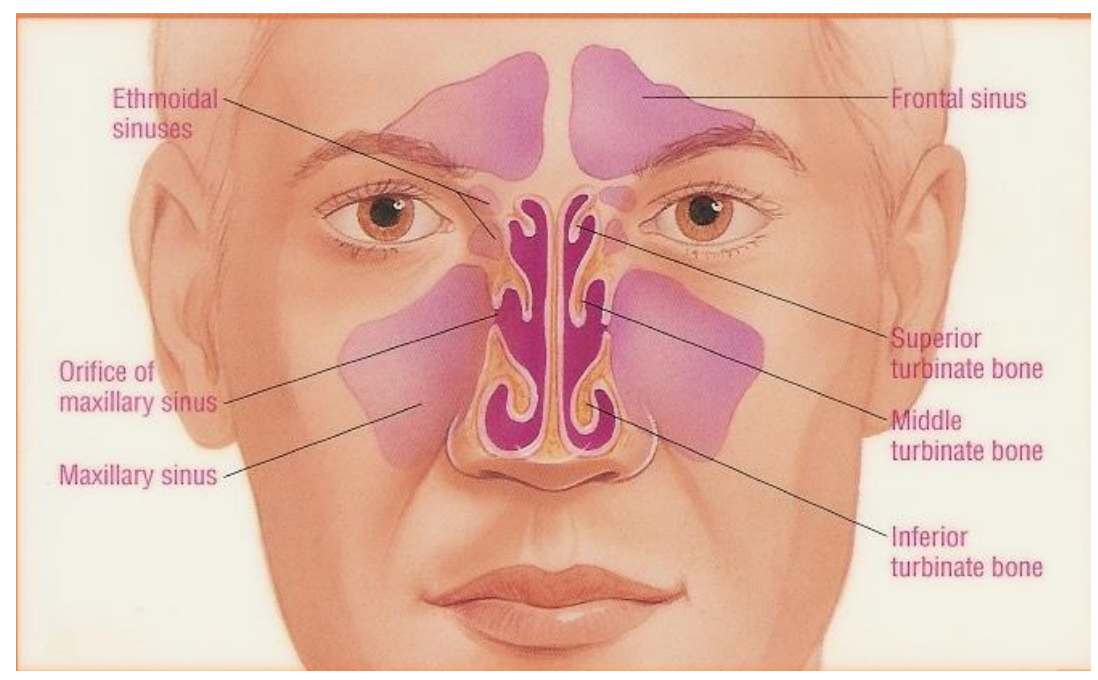

(Otolaryngology Houston 2013) 3

Histologically, allergic nasal polyps are filled with too much fluid and have high counts of white blood cells, more specifically, "a large quantity of extracellular fluid, mast cell degranulation and eosinophilia" (Casale et al 2011). Electron microscope studies of the polyps 
unveil that the surface of the polyp is partially covered by normal, ciliated, respiratory epithelium, disrupted with areas of erosion, damage, and squamous metaplasia. Thus, through metaplasia, the tissue of the polyp is transformed from ciliated columnar epithelium to squamous cells, changing the composition of the surface of the nasal sinus tissue. In addition to the metaplasia, there is also goblet cell and basal cell hyperplasia, which is an increased reproduction of these cells. Underneath this damaged surface epithelium are the basement membrane (lamina reticularis), which begins to thicken, and the stroma of the polyps, which have massive fluid swellings, cyst-like formations, and subepithelial fibrosis with an accumulation of extracellular matrix (Wladislavosky-Waserman 1984). (See Image 4).

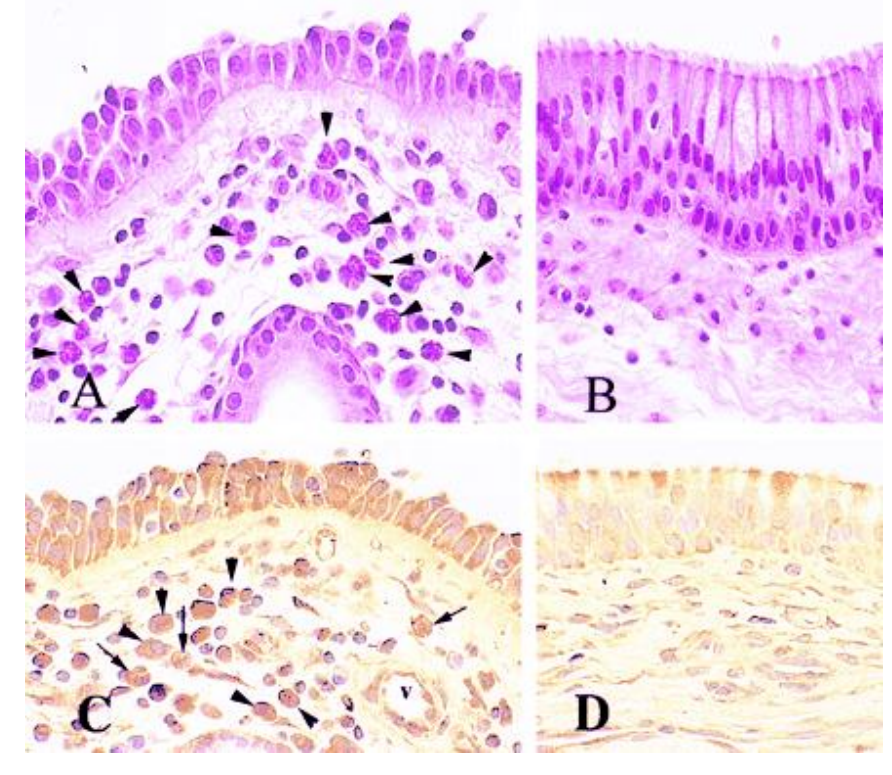

(Ponath 1996)

4

Above is a human nasal polyp (A and C) and adjacent nasal mucosa (B and D) with endothelium lining venules (v), eosinophils (arrows), mononuclear cells (arrowheads). In the contrasting adjacent respiratory tissue, there is normal pseudostratified columnar epithelium and no eosinophil infiltration (B).

Most of the nasal polyp, which is composed of an accumulation of extracellular fluid, or edema, may be caused by severe denervation in polyp tissue with open endothelial junctions of 
venules, causing vascular leakage. Many speculate that this denervation of nasal polyps causes a decrease in secretory activity of the glands and induces an abnormal vascular permeability, leading to an irreversible tissue edema. Nasal polyps develop in areas where the lining of the nasal cavity joins that of the sinuses, and these marginal zones contain thin nerve fascicles (Cauna et al 1972), which may be more sensitive to damage from eosinophil derived proteins (Mygind 1982). Inside the polyp, the accretion of white blood cells, including eosinophils, neutrophils, plasma and mast cells, macrophages, and lymphocytes, is caused by an immune response to fulfill pathogenic defense roles (Hirschberg et al 2003). IgE or Immunoglobin E (an antibody produced in response to an allergic or asthmatic reaction) activates the mast cells, which undergo degranulation, releasing histamine, activating the allergic reaction. The eosinophils also undergo degranulation, producing toxic mediators and a variety of cytokines, chemokines, growth factors, and Interleukin 5, or IL-5, which are secreted from the body's T cells to activate B cells to make more IgE antibodies (Rinia et al 2007). Eosinophils contribute to the polyp formation and growth by causing inflammation and by exerting their effects on extracellular matrix — including stimulation of collagen synthesis and delayed apoptosis (Jankowski 1996). In conjunction with eosinophils, myofibroblasts, which help in a damagerepair response, commonly accumulate in high density in the stem of the polyps. Myofibroblasts play a role in the pathological tissue changes seen in the stem of nasal polyps by producing large amounts of extracellular matrix molecules, such as collagens type I, II, IV, VIII, and fibronectin. Fibroblasts in nasal tissue are activated by growth factor-Beta (TGF- Beta) into myofibroblasts. High levels of this growth factor are secreted by infiltrating eosinophils, and very likely, by the polyp epithelium (Ohno et al 1992). This current cellular-based model of nasal polyp formation can be characterized as inflammatory. According to DeMarcantonio et al 2011, nasal polyposis is 
the "end product of chronic rhinosinusitis," which is a "condition in which the sinuses surrounding the nasal passage become inflamed, or swollen" (Yale School of Medicine 2014). There is also a correlation between the extent of eosinophilia and polyposis severity (Rinia et al 2007). However, much is still unknown as to what is triggering this overwhelming immune response in a specific nasal area. More specifically, the exact reason for the activation of significantly high amounts of eosinophils is unknown, though it has been found that nasal polyposis has a "strong association with allergy, infection, asthma and aspirin hypersensitivity" (Casale et al 2011).

It should be noted that non-eosinophilic polyps exist, in addition to the common eosinophilic nasal polyps. According to Kim et al 2007, $80 \%$ of Western patients with chronic rhinosinusitis and nasal polyposis demonstrate tissue eosinophilia compared with less than $35 \%$ of Korean patients. A study by Zhang et al 2008 confirmed these findings in a comparison of Chinese and Belgian NP patients, finding that non-eosinophilic nasal polyps displayed neutrophilic domination and an upregulation of different interleukins and cytokines (IL-1, IL-6, IL-7, and Th 17) than those of eosinophilic nasal polyps. Similar to eosinophilic nasal polyps, non-eosinophilic polyps also undergo the "production of proinflammatory mediators, fibroblasts, and tissue change" (Chen et al 2005). According to Rinia et al, there are two categories of eosinophilic nasal polyps: allergic and non-allergic. It is widely accepted that eosinophils are a hallmark of allergy, since the eosinophils are attracted by the release of IL-5, though this is not true for non-allergic nasal polyposis patients (Rinia et al 2007). These two categories can be difficult to differentiate because the amount of eosinophilia seems to be the same in both groups, with the same polyp formation. The categories or lack thereof of nasal polyps differ across medical literature, as some studies list specific types of polyps (Stammberger 1997). But, in 
total, most of the studies reviewed showed no categories of polyps at all. Because the categorizations for polyps are varied significantly across studies, it is important to take note that different types of nasal polyps may exist. Typically, nasal polyps are generalized as the edematous, eosinophilic, and allergic types of polyps, with chronic rhinosinusitis. It is important to note the ambiguity in the categorization because, for this particular study, the pathology reports of nasal polyposis do not specify the type of nasal polyp. Rather, the reports generalize simply the presence or absence of nasal polyps and their eosinophils. This ambiguity may or may not factor into the results of the study.

In order to assess the factors that are associated with inflammation in the sinonasal areas that lead to nasal polyp growth, the multifactorial cause of nasal polyps will be focused into four main categories - infections, allergies, asthma, and aspirin hypersensitivity.

\section{Current Hypotheses on Multifactorial Causes of Nasal Polyps}

\subsection{Infections}

There are various hypothesized infectious causes of nasal polyposis, including Staphylococcus aureus and fungus. According to a few studies, there is a significant correlation between the colonization of the nasal mucosa by Staphylococcus aureus and nasal polyposis (Araujo 2003). Other bacteria such as, Staphylococcus pneumonia, Bacteroides fragilis, and Pseudomonas aeruginosa (found in cystic fibrosis) are all common pathogens associated with rhinosinusitis and polyposis. Staphylococcus aureus is present in the mucin adjacent to nasal polyps in about 60 to $70 \%$ of cases of massive nasal polyposis (Pawankar 2003). According to the superantigen hypothesis, Staphylococcus produces toxins - specifically enterotoxins A (SEA) and enterotoxins B (SEB) and Toxic shock syndrome toxin-1 (TSST-1). These toxins may act as 
superantigens, causing the activation and clonal expansion of lymphocytes specifically on the lateral wall of the nose (Bernstein 2005). Th1 and Th2 cytokines are produced by the activated lymphocytes, leading to chronic lymphocytic eosinophilic mucosal disease (Bernstein 2005, Wedi 2002). Th1 messengers help with cell-mediated immunity and macrophage activation or phagocyte-dependent inflammation, while Th2 cells promote strong antibody responses of $\operatorname{IgE}$ and accumulate eosinophils and inhibit phagocyte-independent inflammation (Romagnani 2000). The SAE acts to nonspecifically activate $\mathrm{T}$ cells, thus upregulating and increasing Th2 proinflammatory cytokine levels. In a study, IgE antibodies to SEA and SEB were detected in $50 \%$ of nasal polyp tissue and specific IgE antibodies in serum to SEB and TSST were found in $78 \%$ of polyposis patients (Tripathi 2004). Based on Tripathi's study, there is reason to suspect the presence of Staphylococcus in a majority of nasal polyposis patients.

Though the superantigen hypothesis may explain parts of the possible underlying cause of nasal polyposis, it is not recommended that patients are given antibiotics, specifically penicillinase resistant penicillin, unless tested for bacterial cultures, because of the lack of evidence-based knowledge on the effectiveness in improving the prognosis of patients (Holmström et al 2002). However, recently there has been an increased attentiveness to the role of bacteria in development of nasal polyposis, as stated by Cervin, who claims that a therapy with macrolide antibiotics, specifically Clarithromycin, leads to a significant reduction of polyp size probably not only for its antibacterial activity but also for an anti-inflammatory effect conferred to this class of drugs (Cervin 2001). Dabirmoghaddam et al 2013 also found that macrolide antibiotics decrease the size and symptoms of nasal polyposis, though they acknowledge the need for further study. 
According to DeShazo et al 1995, Fungi are universally found in habitable environments. Commonly inhaled, fungal elements can become trapped in the sinonasal mucus, drawing eosinophils from the respiratory mucosa into the lumen (Kirtsreesakul 2005). This mechanism is still unknown, but once established, eosinophils attack the fungal elements, releasing toxic mediators and causing inflammation. Fungal elements are found histologically in $82 \%$ of chronic rhinosinusitis patients undergoing sinus surgery. However, in a comparison of mucus specimens of chronic rhinosinusitis patients and healthy controls, fungus was present in $96 \%$ and $100 \%$ of the samples, respectively (DeShazo et al 1995). This suggests that fungal colonization is common in the paranasal sinuses, and not only among patients with nasal polyposis. It was also discovered by Weschta et al 2004 that topical amphotericin B nasal spray, which treats fungal elements, was ineffective in treating chronic rhinosinusitis with nasal polyps. On the contrary, a study by Mabry et al 2000, reported that patients with Allergic Fungal Rhinosinusitis (AFRS), caused by Dermatiaceous fungi, had promising results with immunotherapy following surgery (Bent and Kuhn 1996). There is still much to be studied about fungi in nasal polyposis, as it is not universally found in nasal polyposis patients.

\subsection{Allergy}

Aside from bacterial and fungal infections, many researchers find that allergies may be contributing to nasal polyposis. Allergies have been implicated with exacerbating nasal polyposis because of three factors: "the majority of nasal polyps have eosinophilia; the association with asthma; and the nasal findings that may mimic allergic symptoms and signs" (Kirtsreesakul 2005). Furthermore, according to a study by Keith P. Dolovich, polyp patients had a higher prevalence of positive allergy skin tests than the general population (Dolovich 1997). In a 
separate study, patients with positive allergy skin tests were shown to have a higher frequency of multiple nasal polypectomies, or nasal polyp removals, than those with negative allergy skin tests (Pang et al 2000). There is a debate as to whether or not atopic allergies, which are defined as the hereditary allergies that occur with immediate symptoms from exposure to allergens (pollen, dust mites, mold, animal dander, etc.), are associated with nasal polyposis (The UBC Institute of Allergy 2011). According to Caplin et al 1971, only 0.5\% of atopic patients had nasal polyps. However, when looking at an overview of studies on allergy tests in individuals with nasal polyposis, it is evident that there is a higher prevalence of positive allergy skin tests and nasal polyposis than that of the patients without nasal polyposis, with most of the evidence pointing to nasal polyps as a manifestation of a systemic disease (Kirtsreesakul 2005).

\subsection{Asthma}

Asthma is another factor that is often found in conjunction with nasal polyposis. According to a study conducted by Kountakis and Bradley 2003, it was concluded that patients with asthma undergoing Functional Endoscopic Sinus Surgery (FESS) had higher sinus CT grades compared with patients without asthma. Furthermore, asthmatic and non-asthmatic patients had statistically significant reductions in symptom scores after revision FESS. According to a study by Knud Larsen 1996, it was found that asthma developed before polyps in an average of $69 \%$ of the patients. This shows that there is a possibility that asthma may play a role in the development of the polyps. Interestingly, though nasal polyposis appears three times more commonly in males than in females, a woman with polyps is nearly twice more likely to have asthma than a man with polyps (Drake-Lee et al 1984). The reasons behind the associations with sex are still under study. In this same study, again, asthma was found to occur prior to the polyposis. Because data 
suggests that asthma is correlated with nasal polyps, and often comes chronologically before the nasal polyps, it should be regarded as a factor to be studied.

\subsection{Aspirin Hypersensitivity}

Many studies have described aspirin intolerance as a well-known clinical entity with nasal polyposis. Asthma is a "distinct clinical syndrome, characterized by the precipitation of rhinitis and asthma attacks by aspirin and most of other non-steroidal anti-inflammatory drugs (NSAIDS)” (Kirtsreesakul 2005). In most cases of nasal polyposis, persistent rhinitis appears at the average age of 30, then asthma, aspirin intolerance, and lastly, nasal polyps (Szceklik et al 2001). Because asthma and aspirin intolerance are often present with nasal polyposis, patients with these three symptoms are classified as having Samter's triad or aspirin triad. According to a study by Jantti-Alanko et al 1989, it was found that the risk of recurrence of nasal polyposis was significantly greater in patients with ASA hypersensitivity, the frequency of re-operations during the follow-up period was significantly higher in the ASA intolerance group, and the use of topical corticosteroid treatment was also more frequent when compared to groups categorized for atopic allergies and intrinsic diseases.

It is commonly thought that the mechanism behind the aspirin sensitivity has to do with the inhibition of an enzyme called cyclooxygenase (COX). The COX-2 mRNA is often down regulated in nasal polyps of asensitive patients, thus decreasing the release of PGE2 (prostaglandin E2) and an increase in cysteinyl leukotrienes (Picado 2002). Inadequate

production of COX-2 may pre-dispose asthma patients to aspirin hypersensitivity (Picado 2002). Furthermore, increased stimulation of cysteinyl leukotrienes can contribute to an uncontrollable inflammatory response and chronic inflammation (Kirtsreesakul 2005). Thus, aspirin hypersensitivity implies higher inflammation. 


\section{Treatments of Nasal Polyposis}

The reason why patients seek treatment of nasal polyposis, though it is a benign entity, is because of the symptoms that appear with it. This disease can cause nasal obstruction, hyposmia or anosmia, and nasal discharge (Casale et al 2011). Nasal polyposis can be treated in a variety of ways. The most effective treatment used is Functional Endoscopic Sinus Surgery (FESS), which will be discussed in detail later. This surgical procedure involves removing the polyps from the patient. However, other medical treatments can alleviate symptoms and minimize polyps. These treatments include corticosteroids, leukotriene antagonists (antileukotrienes), and antihistamines. According to Casale et al 2011, when considering nasal polyposis as chronic rhinosinusitis, corticosteroids reduce vasodilation, edema, and local deposition of inflammatory mediators. Using topical and systemic corticosteroids is always recommended after polyposis diagnosis because in many cases it leads to a significant reduction of disease degree (Badia et al 2001). In a double-blinded, placebo controlled study of postoperative fluticasone propionate aqueous nasal spray, Rowe-Jones et al 2005 found that the corticosteroid spray decreased edema and improved the polyp scores in the patients. The use of the corticosteroid resulted in an 89\% 5year "survival" with FESS, less polyp recurrence over the 5-year period, and less postoperative medication. Corticosteroids can also be taken orally. Unlike intranasal corticosteroids, oral steroids are limited to short courses because of the risk of systemic adverse effects, such as osteoporosis, GI bleeding, adrenal insufficiency, and complications from uncontrolled diabetics (Bonfils et al 2006).

Some physicians believe that cysteinyl antileukotrienes, such as montelukast, are beneficial for patients with nasal polyposis, particularly with Samter's triad. These leukotriene receptor 
antagonists block the leukotriene receptor sites. Ulualp et al 1999 created a study on 18 patients with Samter's triad and the nasal polyposis disease. 9 patients improved following treatment with the leukotriene antagonists and endoscopic nasal findings were consistent with the reported benefit of the patients' health. Furthermore, multiple studies have shown clinical improvement by those who had CRS with nasal polyposis, demonstrating reduction in polyps, decreased steroid use, and improved overall symptoms (DeMarcantonio and Han 2011). In contrary to this study, a non-placebo controlled study by Parnes and Chuma showed that 40 patients with nasal polyps and chronic sinusitis with improvement in only half of the patients (Parnes and Chuma 2000). Holmström et al 2002 opines that "no convincing data have as yet shown an indication for anti-leukotrienes, in normal or higher doses, in the treatment of nasal polyposis in patients with or without aspirin intolerance."

Antihistamines are usually over-the-counter drugs, often sold as fexofenadine or loratadine to name a few. Patients with nasal polyposis may take these antihistamines even if their use with polyps has not been extensively studied (Casale et al 2011). Antihistamines may be used to alleviate inflammatory symptoms, but are not usually prescribed alone to nasal polyposis patients, due to the lack of data and known effectiveness in decreasing polyps.

\section{$\underline{\text { 4. Functional Endoscopic Sinus Surgery and CT Scoring }}$}

Functional Endoscopic Sinus Surgery (FESS) has long been a successful treatment of nasal polyposis (DeMarcantonio and Han 2011). The endoscopic instrumentation helps to visualize inside the sinonasal cavities with great magnification and clarity. In addition, a shaver can be used to excise the polyps with precision and minimal bleeding. FESS has had success rates reported as high as 85\% (Dufour et al 2004). Though FESS can successfully remove the polyps, it is often reported that patients can lose their sense of smell and still have symptoms. In a study 
by Blomqvist et al 2001, patients reported a reduced sense of smell as one of the worst symptoms associated with nasal polyposis. Furthermore, surgery did not fix the lost sense of smell or olfactory thresholds. The reason for the lost sense of smell is still being studied.

Different patients with certain sets of conjunctive factors (i.e. allergies, asthma, or aspirin hypersensitivity) along with nasal polyposis were reported of having different subjective results from FESS. For example, patients with asthma experienced significant subjective improvements after surgery (Proimos et al 2010). However, those with Aspirin-Exacerbated Respiratory Disease (AERD), or those with aspirin hypersensitivity and nasal polyposis, had much more difficult recoveries from FESS, having poorer recovery in a study of olfaction status after surgery (Albritton et al 2000). Though FESS may not completely eliminate all symptoms experienced by patients with nasal polyposis, by removing the polyps it can be used to dramatically decrease inflammation (DeMarcantonio and Han 2011).

When a surgeon performs the endoscopic sinus surgery, he or she can use an imageguidance surgical navigation system, to help remove the polyps safely and entirely. Using the sinus CT scan with $2 \mathrm{~mm}$ axial cuts, the computer-assisted navigation system allows for the reconstruction of the $\mathrm{CT}$ in three 2-dimensional perspectives of the sagittal, coronal, and axial views. Then, the surgeon can register the patients' surface data interfaced with the computerassisted navigation system, which allows for a probe to be localized on the CT images (Venail et al 2005). This system is commonly used during an endoscopic sinus surgery (See Image $5 \& 6$ ). 


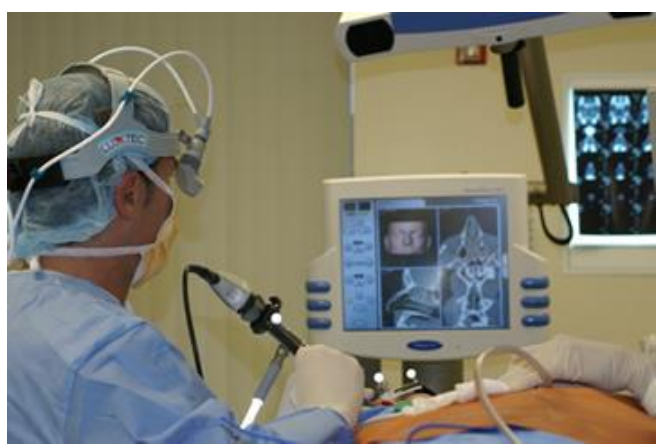

(Scaccia 2012)

5

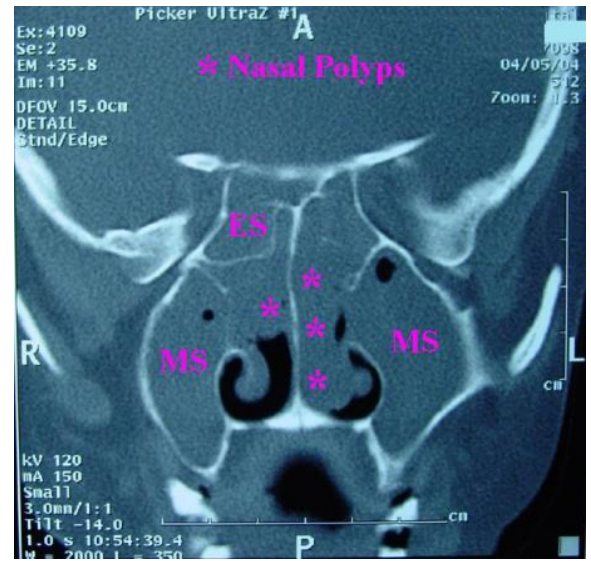

(Kavanagh 2012) 6

ES = Ethmoidal Sinus; MS = Maxillary Sinus; $*$ = Nasal Polyps

Previously, CT imaging scans were mentioned. These Computed Tomography (CT) scans are taken for each patient prior to FESS as a standard protocol. The Lund-Mackay system is used to evaluate the extent of nasal and sinus diseases (See Figure 1).

Figure 1. Lund-Mackay Staging System Chart

\begin{tabular}{|l|}
\hline paranasal sinuses \\
\hline Maxillary $(0,1,2)$ \\
Anterior Ethmoid $(0,1,2)$ \\
Posterior Ethmoid $(0,1,2)$ \\
Sphenoid $(0,1,2)$ \\
Frontal $(0,1,2)$ \\
Ostiomeatal Complex $(0,2)^{*}$ \\
\hline Total \\
\hline Note: 0 - without abnormalities; 1- partial opacification; 2- total opaci- \\
fication \\
*0-no obstruction; 2- obstructed \\
\hline
\end{tabular}

(Boari \& Penteado de Castro 2005) 
Using the Lund-Mackay system, the evaluated scores from the right and left paranasal sinuses for each listed area range, from 0 to 2 . These scores are added to a total score, with a total of 12 for each side. The two scores from the right and left sides can be added to a total score on a scale from 0 to 24 (Lund and Mackay 1993).

\section{Treatment of Allergies with Immunotherapy}

Immunotherapy treatment can be given to a patient subcutaneously (SCIT) or through sublingual immunotherapy (SLIT). Subcutaneous immunotherapy treats the patient in the following manner. The mechanism of action of SCIT includes diminishing allergen-driven Th2 responses, including reductions in IL-4, IL-13, IL-5, and IL-9 levels. The decrease in Th2 markers is complemented by an immune deviation favoring Th1 responses to allergens. SCIT also stimulates immune tolerance by inducing IL-10 and TGF-Beta-secreting T regulatory cells, which presumably suppress Th2 responses. SCIT mediates several beneficial biologic effects, including the ability of post-immunotherapy serum to inhibit binding of allergen-IgE complexes to B cells in vitro, to block IgE-facilitated allergen presentation and activation of allergenspecific T lymphocytes (Saltoun and Avila 2008). Patients are initially tested to determine a safe dose to begin treatment. According to the Wolf and Yun Allergy clinic, subcutaneous immunotherapy is administered on the arm through a subcutaneous injection about twice a week during escalation period until they reach a target concentration, or the maintenance dose. Then, the patients stay on the maintenance dose in order to make maximum antibodies, without an anaphylactic reaction, until the vial is renewed. Each time a new vial is made for treatment, the list of allergens are made and it is decided which allergens are moved up in concentration. Typically, the off-season allergens are moved up in concentration, while the in-season allergens 
are maintained in concentration to prevent any untoward reactions (K. J. Yun MD, oral communication, December 2013).

Sublingual immunotherapy is different from SCIT in that doses are taken orally. SLIT functions in the following mechanism. SLIT is comparable with SCIT in that it also causes regulatory T-cell suppression through IL-10 during the early phase of immunotherapy and specific non-reactivity and immune deviation of allergen-specific $\mathrm{T}$ cells during the later phase of SLIT. However, unlike SCIT, SLIT does not induce production of TGF-Beta, which suggests that SLIT has less ability to generate allergen-specific T regulatory cells. (Saltoun and Avila 2008). Immunotherapy, whether treatment is administered by SCIT or SLIT, helps to decrease allergic reactions and inflammation. According to a study of immunotherapy in patients undergoing FESS by Nishioka et al 1994, it was found that the data "suggests...that allergic patients who undergo immunotherapy do better (twofold to threefold) than those who do not undergo immunotherapy and, with the exception of recurrent polyps, do as well as non-allergic patients...polyp recurrence is higher in allergic patients." Though no data analysis found immunotherapy to be statistically significant in decreasing the recurrence, the raw data demonstrates a very slight trend.

\section{RESEARCH HYPOTHESES:}

In attempt to better understand the development and efficacy of treatment of nasal polyposis, particularly in the Kentucky area, this investigation examined the main contributing factors in polyp recurrence, including allergic, asthma, aspirin hypersensitivity (ASA) causes, and the clinical non-surgical treatments performed, particularly immunotherapy, montelukast and corticosteroids. Due to a lack of information on reported bacterial and fungal infection, these factors were not studied. 
The central hypothesis to this study is that immunotherapy treatment will predict longer time intervals between polyp recurrences and will decrease the likelihood of revision surgeries. Supplementary to this prediction, it is also hypothesized that patients using immunotherapy treatments will also have higher CT scores at the beginning of their first FESS, with the postulation that the patients who are typically with the most severe inflammation will use immunotherapy.

There may be different types of polyps, as described in the Background, which differ across literature. If this is true, then not all of the polyps may show eosinophils. Predicting that allergies and inflammatory diseases are largely contributing to the development of nasal polyps, the number of eosinophilic cases will determine whether the general inflammatory polyps are the most populous type in the local area. Since eosinophilic presence is primarily a characteristic of inflammatory nasal polyps from tissue eosinophilia, and can be found in allergic reactions," the presence of eosinophils is also hypothesized to increase CT scores, or greater severity among patients.

\section{METHODOLOGY:}

\section{Data Collection}

Elizabethtown, Kentucky, the site of the study, is a small city in Kentucky, located in close proximity (45 miles) to Kentucky's largest city, Louisville. The Asthma and Allergy Foundation of America (AAFA) recently released a rank of the worst U.S. cities for spring allergies, naming Louisville as 5th in the country in 2013 (See Image 7 below), and as the top city for 2014. The annual research project identified rankings based on three factors from the 100 largest metropolitan areas, including pollen scores (airborne grass/tree/weed pollen and mold spores), 
the number of allergy medications used per patient, and the number of allergy specialists per patient (Wilson 2014). Top Ten Spring Allergy Capitals

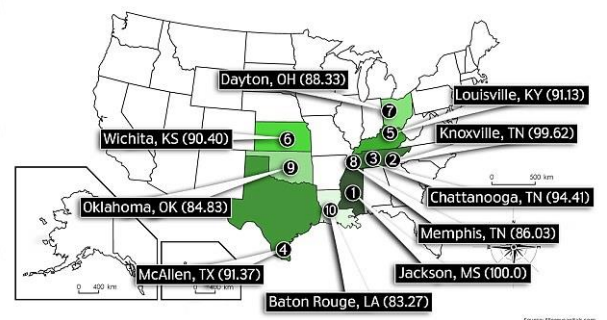

(Daily Mail Reporter 2013)

Despite Elizabethtown's proximity to the worst city for allergies, until very recently in 2014, the city had only two allergy clinics - Wolf and Yun P.S.C. and Central Allergy and Asthma. According to the Wolf and Yun allergy clinic protocol, immunotherapy treatment is the primary treatment for patients with severe allergies, following a positive allergy test through Allergy Skin Testing (AST) or Radioallergosorbent Testing (RAST). Because of the vast overlap on allergy associations with nasal polyposis, as demonstrated in the literature in the Background, it was of interest to find out if eosinophilic dominance in polyp tissue, which is tied with allergies, was associated with the most severe cases of nasal polyposis in the Elizabethtown area. The practice procedural protocol used by ENT physician, Kiro John Yun MD, is as follows. According to Dr. Yun, (oral communication, December 2013), prior to the Functional Endoscopic Sinus Surgery (FESS), patients each have undergone CT imaging, and were assigned a CT score to evaluate the extent of the disease, based on the Lund-Mackay system. After surgical eradication of polyps with Functional Endoscopic Sinus Surgery, patients were evaluated for polyp recurrence with a total follow-up, determined to be the length of time between the last office visit and the date of each patient's first FESS. All patients are recommended allergy testing prior to or after the surgery. Those who tested positive on allergy 
tests are offered immunotherapy treatment. All patients are offered oral corticosteroids for intermittent use and intranasal for continuous use. If a patient returned with obstructive polyps, then revision surgery was recommended.

For the local sample study used for this thesis, I abstracted data from all nasal polyp susceptible patients of Dr. Kiro John Yun, from a ten-year span (2000-2009), with a minimum of 2 years of follow-up. I selected all patients who had undergone endoscopic sinus surgery to remove their polyps and had a confirmed pathological report of having nasal polyps to be included in the study. Of these patients, those who had less than 2 years of follow-up were excluded from the study. I decided to use a 2-year minimum follow-up because it was the average recurrence period of polyps for all patients at the start of the selections. Those who are not within the period from January 1, 2000 - December 31, 2009 were excluded. The remaining patients' charts were used for this study.

I examined each of the patients' charts thoroughly, looking for information regarding demographic and central information to the study. I entered their data into a spreadsheet, using Microsoft EXCEL to keep collection of the data. Starting out with the names of each patient from the charts selected for the study, I replaced their names with an identification number in order to maintain confidentiality and created a separate key in case of necessary referral to patient charts. The EXCEL file listed the patients' birthdates, sexes, dates of first surgeries, dates of last visits, CT scores, presence of eosinophilia, nasal steroid use, oral steroid use, immunotherapy, montelukast use, aspirin hypersensitivity, asthma presence, and dates for first, second, and third revision surgeries (or last revision surgery). Since the allergy patients had electronic charts, I learned to use the computer system to find data that was logged 
electronically. Searching each person's electronic file, I abstracted data on their allergy information to add into the Excel database.

\section{Data Analysis}

The assistance of the University of Louisville School of Public Health's Statistical Consulting Center was utilized to complete the data analysis, under my direction and questions regarding the data analysis of this study. The primary hypothesis, which states that immunotherapy treatment will predict longer time intervals between polyp recurrences and will decrease the likelihood of revision surgeries, was tested in three parts. The first part of this hypothesis was determining whether immunotherapy treatment had any effect on the number of polyp recurrences, by method of utilizing the chi-square test and Fischer's exact test. The number of revision surgeries counted as recurrence events. The chi-square test was used because it allowed one to compare two proportions, the proportions of those on or not on immunotherapy treatment and the proportion of recurrences or no recurrences. The data provides four observed values, with expected values formed from them. The chi-square test then combines the

differences between observed $(\mathrm{O})$ and expected $(\mathrm{E})$, computing a chi-square value $\left({ }^{x^{2}}=\sum \frac{(O-E)^{2}}{E}\right)$. This chi-square value is compared with a reference table of $X^{2}$, specifically identifying a critical value with $n-1$ degrees of freedom ( $\mathrm{n}$ is the number of categories) and with a p-value of 0.05 . If the calculated chi-square value $\left(X^{2}\right)$ exceeds the critical value, then there is a significant difference from the expectation. Since sample size is calculated in the degrees of freedom, a small sample size will cause inaccuracies if a chi-square test is used. Therefore, the Fisher's exact test was used for any analysis of variable proportions with recurrences that had low sample sizes. 
In addition to this hypothesis, it was determined whether immunotherapy treatment increased the probability of a polyp recurrence happening. To conduct this analysis, a Poisson regression was used because the dependent variable of the recurrence events is a count. For the null, the recurrences were assumed to occur randomly, independently of one another, and with an average rate that would not change over time. Relative risks and 95\% confidence intervals for recurrence were generated by category of immunotherapy.

To test if patients with immunotherapy treatment would have higher CT scores, a general linear regression model by the least squares method was used due to the equidistant markers, specifically 1 for "presence," and 0 for "no presence" of immunotherapy treatment. Furthermore, to test if the presence of eosinophils increased CT scores among patients, the linear regression by the least squares method was used due to the equidistant makers, specifically 1 for "presence," and 0 for "no presence." The CT score means were compared for presence and no presence of each variable, determining a p-value to state significant differences between the means.

\section{E. RESULTS:}

Raw Data Table 1.

\begin{tabular}{|l|r|r|r|}
\hline 1.1 Sex: & Male & Female & Total \\
\hline Total Count & 48 & 42 & 90 \\
Average Age (at first year of study) & 47 & 47 & 47 \\
\hline
\end{tabular}

\begin{tabular}{|l|r|r|r|r|}
\hline 1.2 Asthma \& Aspirin Hypersensitivity: & Asthma & Aspirin Hypersensitivity & Samter's Triad & Total \\
\hline Total Count & 28 & 35 \\
\hline
\end{tabular}

\begin{tabular}{|c|c|c|c|}
\hline 1.3 Type of Allergy Testing: & AST & RAST & None \\
\hline Total Count & 73 & 11 & 6 \\
\hline
\end{tabular}

\begin{tabular}{|c|c|c|}
\hline 1.4 Positive Allergy Tests: & Yes & No \\
\hline Total Count & 84 & 0 \\
\hline
\end{tabular}

\begin{tabular}{|c|r|r|r|r|}
\hline 1.5 Eosinophils \& Positive Allergy Test: & Both & Neither & Only Eosinophils & Only Positive Test \\
\hline Total Count & 58 & 5 & 1 & 26 \\
\hline
\end{tabular}


This study of 90 nasal polyposis patients first found demographic information on the patient base. The patient population was nearly split evenly between the males and females. However, as predicted by previously read literature, the male population outnumbered the female population, though not by a 2:1 ratio. There were 48 males and 42 females, out of 90 total patients. Because of the nearly even distribution of sex, this demographic information makes it possible to draw conclusions that are not genetically based. $61 \%$ of the total patient population had neither asthma nor aspirin hypersensitivity. $31 \%$ of the patients had asthma, while $8 \%$ had aspirin hypersensitivity. Only 5.6\% of the total population had Samter's Triad, or a combination of asthma, aspirin intolerance, and nasal polyposis. As previously explained, asthma is typically observed as a predecessor to aspirin hypersensitivity. This may possibly explain the raw data distribution of higher asthma cases than aspirin hypersensitivity cases. Eighty-six out of 90 patients underwent allergy testing. Of these 86, 73 had AST, while 11 had RAST. All those who had been tested had positive results for a list of common allergens (See Appendix). In total, 93\% of the total patient population followed through with allergy testing and had tested positive for common allergies. 6 patients had not had any testing.

Fifty-nine patients out of 90 had eosinophils found in their polyp tissues in the pathology reports. This demonstrates that the majority of the nasal polyposis cases were inflammatory. 58 out of the 59 eosinophilic cases were also tested positive for allergies. One patient with eosinophils did not undergo testing for allergies. Not all patients with positive allergy tests had eosinophils found in their tissue pathology reports. 26 patients had positive allergy tests, but no eosinophils found. This shows that although those with eosinophils may likely have allergies, the reverse is not true. Also, this demonstrates that not all of the nasal polyps in this study did not have an inflammatory characteristic. 
Following examination of the raw data distributions of demographic and contextual information, the central questions to this study were analyzed in the tables found below. Table 1. Summary Statistics.

\begin{tabular}{|c|c|c|c|}
\hline & $\begin{array}{c}\text { Immunotherapy } \\
(\mathrm{n}=70)\end{array}$ & $\begin{array}{c}\text { No Immunotherapy (n } \\
=20)\end{array}$ & \\
\hline Variable Presence & $\mathrm{N}(\%)$ & $\mathrm{N}(\%)$ & $p_{\text {value }}$ \\
\hline Recurrence & $16(22.9)$ & $5(25.0)$ & $1.0000 *$ \\
\hline Eosinophils & $46(65.7)$ & $13(65.0)$ & 0.9527 \\
\hline Asthma & $26(37.1)$ & $2(10.0)$ & $0.0272 *$ \\
\hline Aspirin Hypersensitivity & $6(8.6)$ & $1(5.0)$ & $1.0000 *$ \\
\hline Montelukast Use & $14(20.0)$ & $2(10.0)$ & $0.5078 *$ \\
\hline Steroid Use & $50(71.4)$ & $8(40.0)$ & 0.0096 \\
\hline
\end{tabular}

* Fisher's exact test; others are chi-square.

Table 1 demonstrates the effect of immunotherapy treatment on the number of times a patient undergoes revision surgery. Along with the recurrence counts, this table also depicts the whether the immunotherapy and non-immunotherapy groups were the same with regard to presence of the variables listed, or the presence of tissue eosinophils, asthma, aspirin hypersensitivity, montelukast use, and corticosteroid use. The variables that were found to be significant were presence of asthma and use of steroids. Thus, the proportion of patients who had immunotherapy treatment was more likely to have asthma and use steroids. It is unlikely that individuals in each proportion of asthma or steroid use, between immunotherapy and nonimmunotherapy groups, were drawn from the same underlying distribution. Immunotherapy had no significant effect on the number of revision surgeries.

\footnotetext{
${ }^{1}$ During the data analysis, I re-examined all of the raw data to confirm my entries. Through this review of my raw data, I discovered that three individuals were re-categorized according to immunotherapy. This re-categorization had a significant impact on the final results with respect to those with immunotherapy versus those without immunotherapy, differing drastically according to asthma and steroid use. Noting the dramatic impact of three individuals, changing from insignificant to significant results, is important because it shows how heavily weighted the individuals are in the study, specifically for asthma and steroid use.
} 
Table 2. Poisson Regression: Relative Risks and 95\% Confidence Intervals

\begin{tabular}{|c|c|c|c|}
\hline Variable & $\begin{array}{l}\text { No Immunotherapy } \\
(\mathrm{n}=20)\end{array}$ & $\begin{array}{c}\text { Immunotherapy } \\
(\mathrm{n}=70)\end{array}$ & $\mathrm{p}_{\text {value }}$ \\
\hline $\begin{array}{l}\text { Follow-up time, months, } \\
\text { mean (SE) }\end{array}$ & $76.21(10.26)$ & $67.76(5.48)$ & 0.4697 \\
\hline Events & 5 & 23 & \\
\hline Unadjusted & 1.00 & $1.48(0.56-3.89)$ & 0.4095 \\
\hline Eosinophils & 1.00 & $1.48(0.56-3.90)$ & 0.4071 \\
\hline Asthma & 1.00 & $1.17(0.41-3.34)$ & 0.7742 \\
\hline Aspirin Hypersensitivity & 1.00 & $1.35(0.51-3.59)$ & 0.5337 \\
\hline CT score & 1.00 & $0.98(0.65-2.69)$ & 0.9638 \\
\hline
\end{tabular}

Table 2 shows the effect of immunotherapy on the relative risk of recurrence of nasal polyposis. Using Poisson regression, this table examines how many revision surgeries occurred within the time period with or without immunotherapy. Immunotherapy did not have an effect on the relative risk of recurrence. The relative risk of having a recurring polyp or revision surgery was adjusted separately for eosinophils, asthma, aspirin hypersensitivity, and CT score. When these statistics were adjusted for the covariates of eosinophils, asthma, aspirin hypersensitivity, and CT score, there were no effects.

Table 3. Survival analysis of time to recurrence

\begin{tabular}{|c|c|c|c|}
\hline Variable & $\begin{array}{l}\text { No Immunotherapy } \\
(\mathrm{n}=20)\end{array}$ & $\begin{array}{c}\text { Immunotherapy } \\
(\mathrm{n}=70)\end{array}$ & $p_{\text {value }}$ \\
\hline $\begin{array}{l}\text { Follow-up time, months, mean } \\
\text { (SE) }\end{array}$ & $76.21(10.26)$ & $67.76(5.48)$ & 0.4697 \\
\hline Events (Total Recurrences) & 5 & 23 & \\
\hline Unadjusted & 1.00 & $1.66(0.62-4.44)$ & 0.3166 \\
\hline Eosinophils & 1.00 & $1.66(0.62-4.46)$ & 0.3132 \\
\hline Asthma & 1.00 & $1.40(0.47-4.21)$ & 0.5478 \\
\hline Aspirin Hypersensitivity & 1.00 & $1.49(0.55-4.07)$ & 0.4346 \\
\hline CT Score & 1.00 & $1.04(0.37-2.96)$ & 0.9392 \\
\hline
\end{tabular}

Table 3 shows a survival analysis on the effect of immunotherapy treatment. The Followup time used in this study is defined as the number of FESS removals of polyps over the time between each FESS date, up until the last follow-up date. Immunotherapy had no significant 
effect on the recurrence rates of nasal polyposis. When adjusted with separate models for the covariates of eosinophils, asthma, aspirin hypersensitivity, and CT score, none of the covariates contributed to the outcome.

Table 4. Time to Recurrence and CT Scores

\begin{tabular}{|c|c|c|c|}
\hline Patient ID & Time to Recurrence (Months) & CT Score & Ratio of Time to Recurrence/CT Score \\
\hline 31 & 31.00 & 1 & 31.00 \\
\hline 31 & 23.00 & 1 & 23.00 \\
\hline 21 & 48.00 & 4 & 12.00 \\
\hline 20 & 98.00 & 8 & 12.25 \\
\hline 22 & 42.00 & 8 & 5.25 \\
\hline 22 & 80.00 & 8 & 10.00 \\
\hline 88 & 10.00 & 8 & 1.25 \\
\hline 57 & 2.60 & 9 & 0.29 \\
\hline 8 & 51.00 & 10 & 5.10 \\
\hline 8 & 51.00 & 10 & 5.10 \\
\hline 8 & 78 & 10 & 7.80 \\
\hline 61 & 116.00 & 10 & 11.60 \\
\hline 84 & 48.00 & 10 & 4.80 \\
\hline 60 & 91.00 & 11 & 8.27 \\
\hline 2 & 19.00 & 14 & 1.36 \\
\hline 44 & 45.00 & 15 & 3.00 \\
\hline 54 & 142.00 & 15 & 9.47 \\
\hline 49 & 97.00 & 17 & 5.71 \\
\hline 86 & 32.00 & 20 & 1.60 \\
\hline 86 & 28.00 & 20 & 1.40 \\
\hline 34 & 22.00 & 22 & 1.00 \\
\hline 37 & 43.00 & 22 & 1.95 \\
\hline 70 & 10.00 & 23 & 0.43 \\
\hline 70 & 93.00 & 23 & 4.04 \\
\hline 56 & 9.00 & 24 & 0.38 \\
\hline 56 & 79.00 & 24 & 3.29 \\
\hline 74 & 34.00 & 24 & 1.42 \\
\hline 81 & 19.00 & 24 & 0.79 \\
\hline
\end{tabular}

Table 4 lists patients with their time intervals between FESS in months, with their CT score and a ratio of their time to recurrence, divided by CT score. The time intervals, or the time to recurrence, were the number of months between Functional Endoscopic Sinus Surgeries. Patients with multiple recurrences are listed separately, with the same CT score, but different time intervals. 
Figure 2. CT Score and Ratio of Time to Recurrence/CT Score

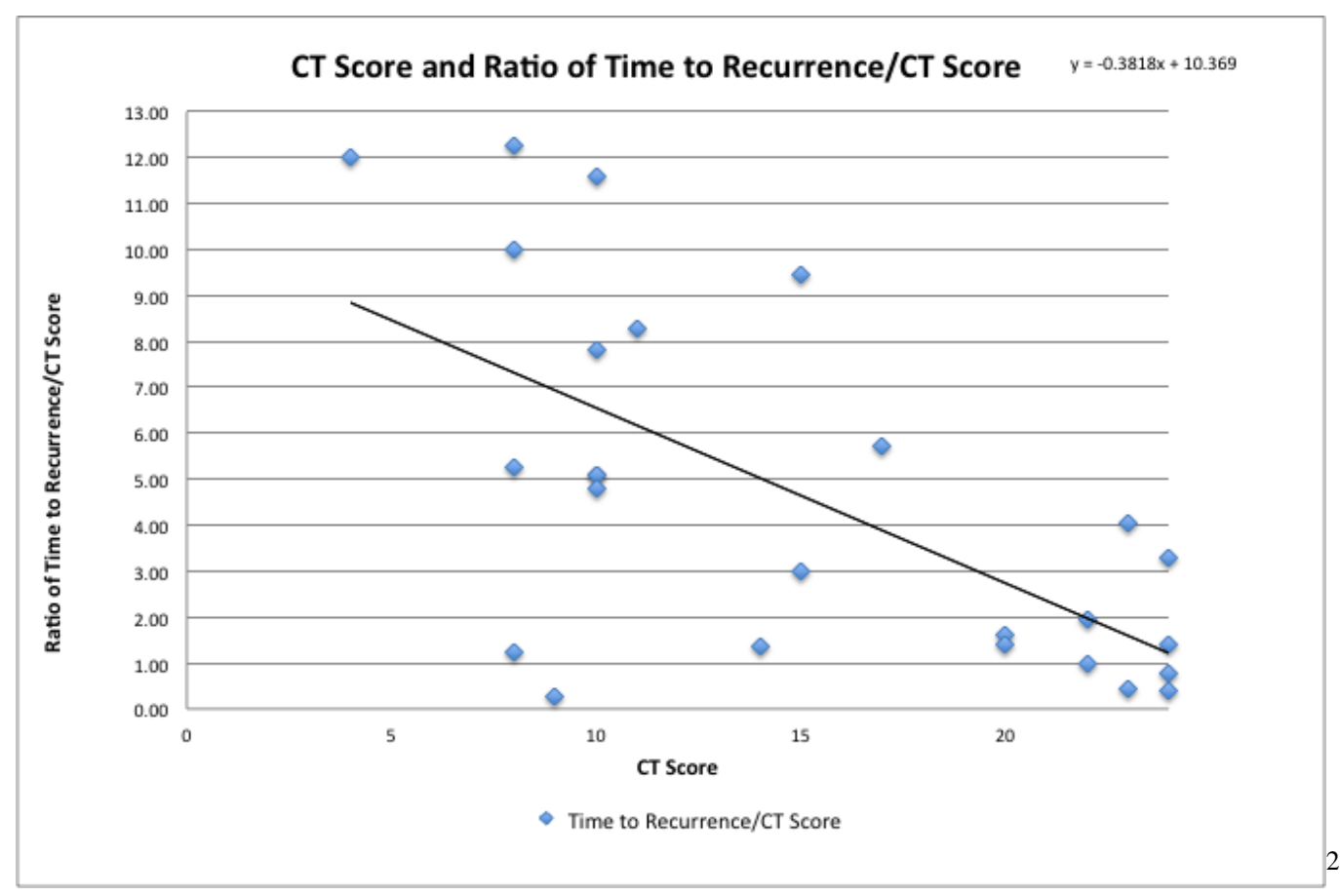

Figure 2 depicts a graph of Table 4 . In this scatter plot, the ratio of time to recurrence over CT score is plotted against the CT scores. When plotting the ratio, scaling time to recurrence by CT score through ratios make the pattern more apparent. In this figure, the ratio becomes smaller as the length of time decreases and the CT score increases. If the patients have a shorter time to recurrence and a higher CT score, then they will have a lower ratio. The length of time to recurrence decreases by 0.38 times for higher $\mathrm{CT}$ scores.

Table 5. CT Scores.

\begin{tabular}{|c|c|c|c|}
\hline & Not Present & Present & \\
\hline Variable & mean \pm se & mean \pm se & $p_{\text {value }}$ \\
\hline Immunotherapy & $7.30 \pm 1.40$ & $12.04 \pm 0.75$ & 0.0036 \\
\hline Eosinophils & $9.61 \pm 1.16$ & $11.71 \pm 0.84$ & 0.1481 \\
\hline Asthma & $9.92 \pm 0.81$ & $13.36 \pm 1.21$ & 0.0199 \\
\hline Aspirin Hypersensitivity & $10.42 \pm 0.69$ & $17.71 \pm 2.37$ & 0.0040 \\
\hline
\end{tabular}

\footnotetext{
${ }^{2}$ The graph of the table, without adjustments, showed that individual \#31 was most likely an outlier. This individual was taken out of the graph shown in Figure 2.
} 
Table 5 examines whether the use of immunotherapy will result in higher CT scores. In this table, patients not on immunotherapy have an average CT score mean of 7.30. Those using immunotherapy, have a CT score of 12.04. Since the p-value is significant at 0.0036 , it can be concluded that patients on immunotherapy treatment are more likely to have an increased CT score, and thus a more severe case of nasal polyposis. In addition, this table shows whether the presence of eosinophils will result in a higher CT score. Those who had eosinophils versus those who did not have eosinophils did not differ greatly in their CT score means. Thus, the presence of eosinophils did not affect the CT score of the patients. With a low p-value of 0.0199 , the patients with asthma were more likely to have higher CT scores. Those with aspirin hypersensitivity were very likely to have an even higher CT score, with a p-value of 0.0040 . This result implies that aspirin hypersensitivity may be associated with more severe cases of nasal polyposis in this sample study.

Figure 3. Follow Times.

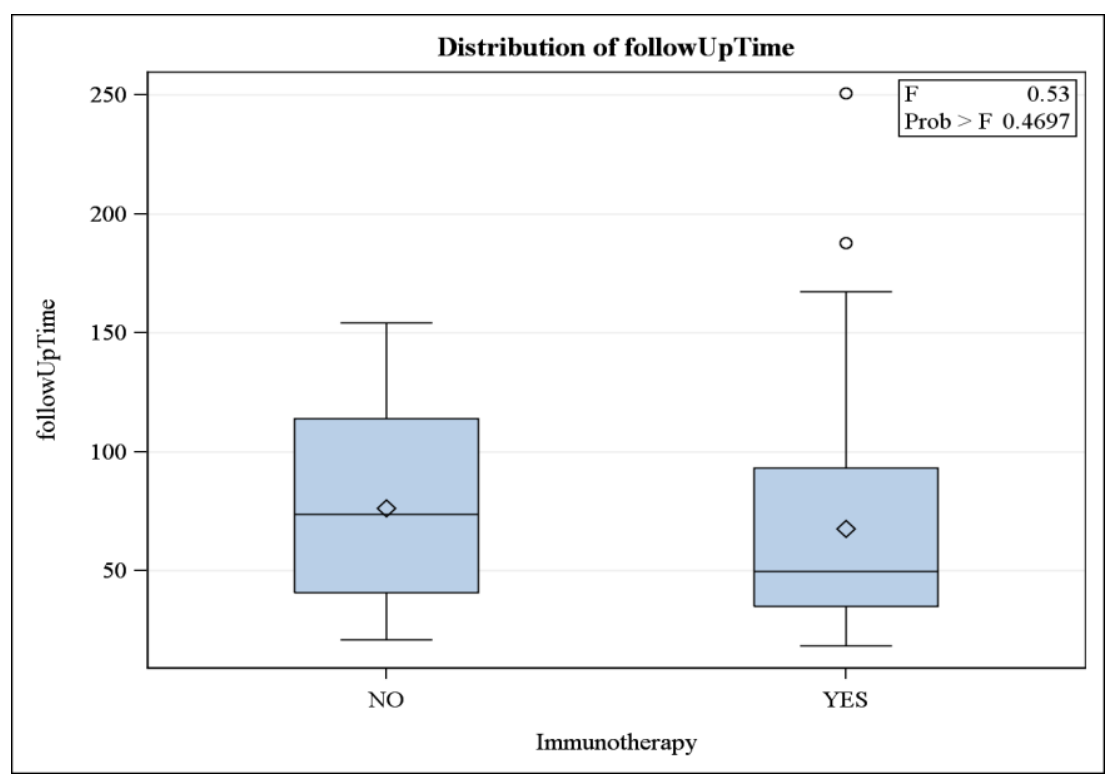

Figure 3 illustrates the follow-up times of patients with and without immunotherapy treatment. In the X-axis, those not using immunotherapy treatment are in the "NO" category and 
those using immunotherapy treatment are in the "YES" category. The Y-axis was measured for the number of months between the date of the first FESS and the final follow-up date. Patients who were using immunotherapy treatment had a longer follow-up time maximum. There were 2 outliers, with immunotherapy, in this graph. The average distribution of follow-up time for those not on immunotherapy was slightly longer than the mean follow-up time of those on immunotherapy treatment. However, the differences between these two groups was not significant. Thus, the analysis of the recurrences and effect of immunotherapy can be interpreted independently of the total time following the patients.

\section{F. STRENGTHS \& LIMITATIONS:}

There were many strengths and limitations in this retrospective study. Due to the retrospective nature, it was difficult to control for various variables in the sample population. However, some control was achieved through the layout of this study, strengthening its validity. Only one surgeon operated on all of the 90 patients, creating consistency in FESS for each patient. In addition, pathology reports were used to maintain the consistency across all patients. Nevertheless, striving to create uniformity prevented accuracy in testing for associated factors. For example, the presence of eosinophils was used as an indicator of inflammation. Also, allergy tests were not taken universally among all of the patients, so the allergy test results were not used as a covariate. This limited the study in finding the direct relevance of allergies in the recurrence values. Because eosinophils were detected by pathology reports that were universal to the sample population, the eosinophilic presence was a primary indication of inflammation and could serve as a secondary indication of allergic symptoms. Since this was a retrospective study, there was no way to control the allergy testing for all of the patients because it was already in the past. This could create a bias for those who may not have had the financial means to get tested. Another 
limitation to this study was that each of the treatments used had varying durations and timings for each individual patient. These could not be controlled for in this study. Because of efforts to maintain consistency, the patient base was limited to one practice. However, due to this controlled criteria, the small sample size of 90 may have made the analysis challenging in that significance was difficult to attain.

The study was successful in utilizing a universal system of scoring for all of the patients to compare CT scores. The subjectivity of scoring the $\mathrm{CT}$ also attained precision by using one scorer throughout all of the patient cases. As described in the section, "Functional Endoscopic Sinus Surgery and CT Scoring," the Lund-Mackay system is a calculation of the left and right sinonasal areas, with a total of 12 for each side and 24 total. But because of the nature of this staging system, there was a limitation in the interpretation of it. For example, if a patient had a severe right side with a score of 12 , one could not differentiate this score with another patient with scores of 6 for each side. The experiment could have been improved if CT scores were available unilaterally and for each FESS, particularly for the recurrences. In retrospect, the study could have also been made more accurate if the date of the polyp diagnosis, prior to the actual surgery, was recorded as the recurrence events, rather than the revision surgeries.

A prospective study could allow for the mentioned limitations to be reduced by the following ways: 1) increase the patient sample size, 2) standardize allergy testing, 3) conduct a double-blinded and placebo-controlled test for treatments, 4) include lateral scores of the LundMackay scoring for each revision CT scan and 5) determine dates of polyp appearance instead of removal. Overall, this study had much strength in maintaining constancy in the criteria that could be controlled. 


\section{G. CONCLUSIONS:}

The objective of this study was to find out if immunotherapy treatment would predict longer time intervals between polyp recurrences and would decrease the likelihood of revision surgeries. According to Table 1, there was not a statistically significant difference in the numbers of recurrence between the immunotherapy and non-immunotherapy groups. Other variables were reviewed in these results as well. It was found that patients who had immunotherapy treatment were more likely to have asthma. Also, those who had immunotherapy treatment were more likely to use corticosteroids. There are some possible explanations for these results. First, asthma can be exacerbated by allergens. Most likely, patients with severe allergies, who were on immunotherapy, were also asthmatic. Secondly, because topical corticosteroids are often prescribed universally among patients and intermittently for oral steroids, it is not surprising to see that there is overlap between immunotherapy treatments and corticosteroid treatments. The rest of the variables tested in Table 1 were considered insignificant by a high p-value. According to Table 2, the immunotherapy group did not have a greater relative risk of recurrence of polyps. When adjusted for covariates, there were no effects. Immunotherapy patients did not show an increased rate of polyp recurrence, with lower time intervals between FESS events. Therefore, this study failed to reject the null hypothesis.

In addition to the main hypothesis, it was hypothesized that patients using immunotherapy treatments would have higher CT scores. This hypothesis was not rejected. According to Table 5, the immunotherapy was correlated with a higher CT score. The p-value was significant at 0.0036 . The patients on immunotherapy treatment were more likely to have an increased CT score. This could possibly be explained by the idea that patients with immunotherapy may present more severe inflammation and thus higher CT scores. 
When examining the effect of recurrence rates based on the CT score, the higher CT scores had a shorter time to recurrence by 0.38 times. This study also determined whether the general inflammatory polyps were the most populous type in the local study and whether the presence of eosinophils increased CT scores. From the raw data counts, it was apparent that most of the patients did have inflammatory, eosinophilic polyps. Also, when analyzing the effect of eosinophils on CT scores, Table 5 shows that the presence of eosinophils had no effect on increasing the $\mathrm{CT}$ scores. This finding adds to the current literature in that a differentiation between the eosinophilic and non-eosinophilic polyps can better determine the effectiveness of treatment strategies. In addition to this finding, aspirin hypersensitivity was found to be the factor associated with the highest CT score, with asthma second in causing higher CT scores. In the results, the mean $\mathrm{CT}$ score of the aspirin hypersensitive patients was 17.71 , while those with asthma had an average CT score of 13.36. Thus, it is evident that the factor of aspirin hypersensitivity is associated with the highest CT score. This finding agrees with current literature that aspirin hypersensitivity exacerbates nasal polyp inflammation.

Overall, the location of Elizabethtown as proximate to the top allergy capital in the US was indicative of a high number of positive allergy cases among nasal polyposis patients, with $93 \%$ of the total population tested in the raw data. However, tissue eosinophilic presence had no association with more severe disease. Aspirin hypersensitivity was correlated with the most severe nasal polyposis cases. Immunotherapy treatment was not statistically significant in successfully lowering the number of nasal polyposis recurrences and extending the time interval between recurrences. Increasing the $\mathrm{CT}$ score indicated a faster recurrence.

It may save money, time, pain, and surgical risk to advise a nasal polyposis patient to undergo FESS with the earliest finding of nasal polyps or with the lowest CT score possible. 
This also means that early surgical intervention may be necessary for patients, regardless of symptom presence. However, surgical risk should also be considered. Therefore, it is recommended that physicians detect nasal polyposis in early stages and intervene surgically. Other medicinal treatments may be more effective in keeping inflammation low due to open paranasal sinuses from the eradication of polyps. Further studies need to be conducted to verify these results and to determine the cause of nasal polyposis and the effects of immunotherapy treatment. 


\section{H. APPENDIX:}

List of common allergens tested at Wolf and Yun PSC.

- Grasses
○ Johnson
○ Timothy
- Bahia
○ Bermuda

- Ragweeds

○ Common (Short)

- Giant

- Weeds

○ Lamb's Quarter

- English Plantain

○ Pigweed, Rough

- Trees

○ Maple (Box Elder)

- Oak (White)

- Cottonwood, Eastern

- Red Cedar

- Dust

- D. pternoxssinus Mite

- D. farinae Mite

- Cockroach, American

- House Dust

- Epidermal

- Dog, Hair and Epithelium

- Cat, Hair

- Molds

○ Fusarium vasifetum

- Helminthosporium sativum

- Penicillium notatum

- Aspergillus fumigatus

- Alternarla tenuis

- Hormodendrum cladosporioides

- Cephalosporium

- Trichophyton

- Candida albicans

- Epidermophyton floccosum

- Miscellaneous

- Tobacco Leaf

- Oris Root

- Horse Hair

- Cow Hair

- Goldenrods 


\section{BIBLIOGRAPHY:}

Albritton, F. D., \& Kingdom, T. T. (2000). Endoscopic sinus surgery in patients with cystic fibrosis: an analysis of complications. American Journal of Rhinology, 14(6), 379-85.

Araujo, E., Palombini, B. C., Cantarelli, V., Pereira, A., \& Mariante, A. (2003). A Microbiology of middle meatus in chronic rhinosinusitis. American Journal of Rhinology, 17(1). Retrieved from 9-15

Badia, L., \& Lund, V. (2001). Topical corticosteroids in nasal polyposis. Drugs, 61(5), 573-578.

Baroody, F. M., \& Emani, J. (2010). History of nasal polyposis. Nasal Polyposis, 1(1), 1-7.

Bent, J. P., \& Kuhn, F. A. (1996). Allergic Fungal Sinusitis/Polyposis. Allergy and Asthma Proc, 17(5), 259-268.

Bernstein, J. M., \& Kansal, R. (2005). Superantigen hypothesis for the early development of chronic hyperplastic sinusitis with massive nasal polyposis. Current Opinion in Otolaryngology \& Head and Neck Surgery, 13(1), 39-44. doi:10.1097/00020840200502000-00010

Blomqvist, E. H., Lundblad, L., Anggard, A., Haraldsson, P., \& Stjarne, P. (2001). A randomized controlled study evaluating medical treatment versus surgical treatment in addition to medical treatment of nasal polyposis. Journal of Allergy and Clinical Immunology, 107(2), 224-228.

Boari, L., \& Penteado de Castro Júnior, N. (2005). Diagnosis of chronic rhinosinusitis in patients with cystic fibrosis: correlation between anamnesis, nasal endoscopy and computed tomography. Revista Brasileira de Otorrinolaringologia, 71(6). Retrieved from http://dx.doi.org/10.1590/S0034-72992005000600003 
Bonfils, P., Halimi, P., \& Malinvaud, D. (2006). Adrenal suppression and osteoporosis after treatment of nasal polyposis. Acta Otolaryngol, 126, 1195-1200.

Caplin, I., Haynes, T. J., \& Spahn, J. (1971). Are nasal polyps an allergic phenomenon?Annals of Allergy, 29, 631-4.

Casale M., Pappacena M., Potena M., Vesperini E., Ciglia G., Mladina R., Dianzani C., et al. (2011). Nasal polyposis: From pathogenesis to treatment, An update. Inflammation \& Allergy-Drug Targets, 10, 158-163.

Cauna, N., Hinderer K. H., Manzetti G. W., et al. (1972) Fine structure of nasal polyps. Ann Otol Rhinol Laryngol, 81, 41-48.

Cervin, A. (2001). The Anti-inflammatory Effect of Erythromycin and its Derivatives, with Special Reference to Nasal Polyposis and Chronic Sinusitis. Acta Otolaryngologica,121(1), 83-92. doi:10.1080/000164801300006326

Chen, Y. S., Arab, S. F., \& Westhofen, M. (2005). Expression of interleukin-5, interleukin-8, and interleukin-10 mRNA in the osteomeatal complex in nasal polyposis. American Journal of Rhinology, 19(2), 117-123.

C/V ENT Surgical Group (2009). Nasal and Sinus Surgery. Retrieved April 2, 2014, from http://www.cvsurgicalgroup.com/services/sinus-surgery/

Dabirmoghaddam, P., Seraj, J. M., Bastaninejad, S., Meighani, A., \& Mokhtari, Z. (2013). The efficacy of clarithromycin in patients with severe nasal polyposis. Acta Medica Iranica, 51(6), 359-364.

Daily Mail Reporter (2013, April 2). Jackson in Mississippi is 'allergy capital' of the US due to high pollen count. Retrieved April 2, 2014, from http://www.dailymail.co.uk/news/article2303149/Jackson-Mississippi-allergy-capital-US-high-pollen-count.html 
DeMarcantonio, M. A., \& Han, J. K. (2011). Nasal Polyps: Pathogenesis and Treatment Implications. Otolaryngologic Clinics of North America, 44, 685-695. doi:10.1016/j.otc.2011.03.005

DeShazo, R. D., \& Swain, R. E. (1995). Diagnostic criteria for allergic fungal sinusitis.Journal of Allergy and Clinical Immunology, 96, 24-35. doi:10.1016/S0091-6749(95)70029-3

Dolovich, K. P. (1997). Nasal polyposis: an inflammatory disease and its treatment.Journal of Allergy and Nasal Polyposis, 68-77.

Drake-Lee, A. B., Lowe, D., Swanston, A., \& Grace, A. (1984). Clinical Profile and recurrence of nasal polyps. Journal of Laryngology and Otology, 98, 783-793.

Dufour, X., Bedier, A., \& Ferrie, J. C. (2004). Diffuse nasal polyposis and endonasal endoscopic surgery: long-term results, a 65-case study. Laryngoscope, 114(11), 1982-7.

Hirschberg A., Darvas A., Almay K., Repassy G., Falus A. (2003). The Pathogenesis of Nasal Polyposis by Immunoglobulin E and Interleukin-5 Is Completed by Transforming Growth Factor- $\beta 1$. The Laryngoscope, 113, 120-124.

Holmström, M., Holmberg, K., Lundblad, L., Norlander, T., \& Stierna, P. (2002). Current Perspectives on the Treatment of Nasal Polyposis: A Swedish Opinion Report. Acta Otolaryngologica, 122, 736-744. doi:10.1080/003655402/000028065

Jankowski, R. (1996). Eosinophils in the pathophysiology of nasal polyposis. Acta Otolaryngol, 116, 160-3.

Jantti-Alanko, S., Holopainen, E., \& Malmberg, H. (1989). Recurrence of nasal polyps after surgical treatment. Rhinology, 8, 59-64.

Kavanagh, K. (2012). Nasal (Nose) Pictures and Photos. Retrieved April 2, 2014, from http://www.entusa.com/nose_photos.htm 
Kim, J., Hong, S., Kim, Y., Lee, C. H., Min, Y., \& Rhee, C. (2007). Histological and immunological features of non-eosinophilic nasal polyps. Otolaryngology-head and Neck Surgery. doi:10.1016/j.otohns.2007.07.036

Kirtsreesakul, V. (2005). Update on Nasal Polyps: Etiopathogenesis. Journal of The Medical Association of Thailand, 88(12), 1966-1972.

Kountakis, S. E., \& Bradley, D. T. (2003). Effect of asthma on sinus computed tomography grade and symptom scores in patients undergoing revision functional endoscopic sinus surgery. American Journal of Rhinology, 17(4), 215-219.

Larsen, K. (1996). The Clinical Relationship of Nasal Polyps to Asthma. Allergy and Asthma Proceedings, 17(5), 243-249. doi:10.2500/108854196778662255

Larson P. L., Tos M., Baer S. (1994). En block removal of the ethmoid and ostiomeatal complex in cadavers, with a practical application. Rhinology, 32, 62-64.

Larson P. L., Tos M., Kuijpers W., van der Beek J.M.H. (1992). The early stages of polyp formation. Laryngoscope, 102, 670-677.

Learn Human Anatomy (2014). Nasal Cavity. Retrieved April 2, 2014, from http://learnhumananatomy.com/nasal-cavity/

Lund, V. J., \& Mackay, I. S. (1993). Staging in rhinosinusitis. Rhinology, 107, 183-4.

Mabry, R. L., Marple, B. F., \& Mabry, C. S. (2000). Outcomes after discontinuing immunotherapy for allergic fungal sinusitis. Otolaryngology Head Neck Surgery, 122, 1046.

Mayo Clinic Staff. (2011). Diseases and conditions of nasal polyps. Mayo Clinic. http://www.mayoclinic.org/diseases-conditions/nasal-polyps/basics/definition/con20023206. Accessed January 10, 2014. 
Motulsky, H. (1995). Intuitive biostatistics. New York: Oxford University Press.

Mygind, N. (1982) Nasal polyposis. Editorial. J Allergy Clin Immunol, 86, 827-829.

Nishioka, G. J., Cook, P. R., Davis, W. E., \& McKinsey, J. P. (1994). Immunotherapy in patients undergoing functional endoscopic sinus surgery. Otolaryngology Head and Neck Surgery, 110, 406-412.

Ohno, I., Lea, R. G., Flanders, K. C., Clark, D. A., Banwatt, D., Dolovich, J., . . Jordana, M. (1992). Eosinophils in chronically inflamed human upper airway tissues express transforming growth factor beta 1 gene (TGF beta 1). Journal of Clinical Investigation, 89, 1662-1668. doi:10.1172/JCI115764

Otolaryngology Houston (2013, March 24). Anatomy of the sinuses. Retrieved April 2, 2014, from http://www.ghorayeb.com/anatomysinuses.html

Pang, Y. T., Eskici, O., \& Wilson, J. A. (2000). Nasal polyposis: role of subclinical delayed food hypersensitivity. Otolaryngology Head and Neck Surgery, 122, 298-301.

Parnes, S. M., \& Chuma, A. V. (2000). Acute effects of antileukotrienes on sinonasal polyposis and sinusitis. Ear Nose Throat Journal, 79, 18-25.

Pawankar, R. (2003). Nasal polyposis: an update. Current Opinion in Allergy and Clinical Immunology, 3, 1-6. doi:10.1097/00130832-200302000-00001

Picado, C. (2002). Aspirin intolerance and nasal polyposis. Current Allergy and Asthma Reports, 2(6), 488-93. doi:10.1007/s11882-002-0089-8

Ponath, P. D. (1996, February). Photomicrographs of human nasal polyp and adjacent nasal mucosa [Photomicrographs ]. Retrieved from http://www.phoenixbiotech.net/catalog/pnxfoget.php?id=pnxnews_000000385\&title=Com pound\&sum=Function 
Proimos, E., Papadakis, C. E., \& Chimona, T. S. (2010). The effect of functional endoscopic sinus surgery on patients with asthma and CRS with nasal polyps.Rhinology, 48(3), 331-8.

Rinia A.B., Kostamo K., Ebbens F. A., van Drunen C. M., Fockkens W. J. (2007). Nasal polyposis: a cellular-based approach to answering questions. Allergy, 62, 348-358.

Romagnani, S. (2000). T-cell subsets (Th1 versus Th2). Annals of Allergy Asthma \& Immunology, 85(1), 9-18. doi:10.1016/S1081-1206(10)62426-X

Rowe-Jones, J. M., Medcalf, M., Durham, S. R., Richards, D. H., \& Mackay, I. S. (2005). Functional Endoscopic Sinus Surgery: 5 year follow up and results of a prospective, randomised, stratified, double-blinded, placebo controlled study of postoperative fluticasone propionate aqueous nasal spray. Rhinology, 43, 2-10.

Saltoun, C., \& Avila, P. C. (2008). Advances in upper airway diseases and allergen immunotherapy in 2007. Journal of Allergy and Clinical Immunology, 122(3), 481-7. doi:10.1016/j.jaci.2008.06.027

Scaccia, F. (2012). Sinus surgery. Retrieved April 2, 2014, from http://www.riversideface.com/pages/tour.html

Settipane, G. A. (1996). Epidemiology of nasal polyps. Allergy Asthma Proc., 17, 231-6.

Stammberger, H. (1997). Examination and endoscopy of the nose and paranasal sinuses. In Nasal polyposis: an inflammatory disease and its treatment (pp. 120-36). Coponhagen, Denmark: Munksgaard.

Szceklik, A., Nizankowska, E., Sanak, M., \& Swierczynska, M. (2001). Aspirin-induced rhinitis and asthma. Current Opinion in Allergy Immunology, 1, 27-33. 
The UCB Institute of Allergy (2011, September 12). Atopy versus allergy. Retrieved April 2, 2014, from http://www.theucbinstituteofallergy.com/patient-and-public/What-isAllergy/How-does-allergy-develop/Atopy-versus-allergy

Tripathi, A., Conley, D. B., Grammer, L. C., Ditto, A. M., Lowery, M. M., \& Seiberling, K. A. (2004). Immunoglobulin E to Staphylococcal and Streptococcal toxins in patients with chronic sinusitis/nasal polyposis. Laryngoscope, 114, 1822-6.

Ulualp, S. O., Sterman, B. M., \& Toohill, R. J. (1999). Antileukotriene therapy for the relief of sinus symptoms in aspirin triad disease. Ear Nose Throat Journal, 78(8), 604-613.

Venail, F., Garrel, R., Makeieff, M., Guerrier, B., \& Crampette, L. (2005). Sinus navigation: contribution and limitations. Fr ORL, 86, 23-28.

Wedi, B., Wieczorek, D., Stunkel, T., Breuer, K., \& Kapp, A. (2002). Staphylococcal exotoxins exert proinflammatory effects through inhibition of eosinophil apoptosis, increased surface antigen expression (CD11b, CD45, CD54, and CD69), and enhanced cytokine-activated oxidative burst, thereby triggering allergic inflammatory reactions. Journal of Allergy and Clinical Immunology, 109, 477-484.

Weschta, M., Rimek, D., Formanek, M., Polzehl, D., Podbielski, A., \& Riechelmann, H. (2004). Topical antifungal treatment of chronic rhinosinusitis with nasal polyps: A randomized, double-blinded clinical trial. Journal of Allergy and Clinical Immunology,113, 1122-8. doi:10.1016/j.jaci.2004.03.038

Wilson, J. (2014, March 31). Worst U.S. cities for spring allergies - CNN.com. Retrieved April 2, 2014, from http://www.cnn.com/2014/03/31/health/worst-allergy-citiesspring/ 
Wladislavosky-Waserman, P., Kern, E.B., Holley, K. E., Eisenbrey, A. B., \& Gleich, G. J. (1984). Epithelial damage in nasal polyps. Clinical and Experimental Allergy, 14(3), 241-7. doi:10.1111/j.1365-2222.1984.tb02203.x

Yale School of Medicine (2014, February 6). Chronic Rhinosinusitis: Sinus \& Allergy. Retrieved April 2, 2014, from http://medicine.yale.edu/surgery/otolaryngology/sinusallergy/patient/conditions/chronicrhinosinusitis.aspx\#page 1

Zhang, N., Van Zele, T., \& Perez-Novo, C. (2008). Different types of T-effector cells orchestrate mucosal inflammation in chronic sinus disease. Journal of Allergy and Clinical Immunology, 122(5), 961-8. 